\title{
KSIĘŻA DOKTORZY HONORIS CAUSA UNIWERSYTETU JAGIELLOŃSKIEGO (1809-1931)
}

W dniu 22 czerwca 1983 roku w Collegium Maius Uniwersytetu Jagiellcńskiego odbyła się podniosła uroczystość wręczenia dyplomu doktora honoris causa Ojcu Świętemu Janowi Pawłowi II. W ponad sześćsetletnich dziejach Almae Matris Jagellonicae akt ten nabrał niejako znaczenia symbolu. Wpisując Ojca Świętego w poczet doktorów honorowych, Uniwersytet Krakowski przełamał ostatecznie bariere narzuconego mu przed laty pozanaukowego kryterium w przyznawaniu tego rodzaju wyróżnienia akademickiego. Nawiązano bowiem do dawnej tradycji nadawania tego zaszczytnego tytułu wybitnym osobom niezależnie od ich przekonań czy postawy ideowej, a wyłącznie $\mathrm{z}$ powodu istotnych osiągnięć naukowych, bądź też z racji zasług położonych dla Narodu Polskiego i dla naszej Ojczyzny, czy też po prostu dla samego Uniwersytetu. Wspominając te niezapomniane chwile z Ojcem Świętym w Collegium Maius, warto może przypomnieć przy tej okazji tych wszystkich duchownych katolickich, których krakowska Uczelnia obdarzyła w przeszłości doktoratem honorowym.

Tradycja nadawania w Uniwersytecie Jagiellońskim tytułu doktora honorowego sięga początku XIX wieku. Wprowadzając tę formę wyróżnienia, Alma Mater Jagellonica szła w tym przypadku śladem wzorów obcych, bezpośrednio — jak wolno przypuszczać - płynących ze wszechnic niemieckich. W uczelniach tych zwyczaj nadawania doktoratów honoris causa sięga czasów odleglejszych niż to miało miejsce w Krakowie. Taką możliwość wykorzystał np. Wydział Filozoficzny Uniwersytetu Wrocławskiego, dokonując w dniu otwarcia tej wszechnicy (19 X 1811) pierwszej w jej dziejach promocji doktorskiej honoris causa. Kontynuowano w tym przypadku tradycję odziedziczoną po Uniwersytecie z Frankfurtu nad Odrą, właśnie w r. 1811 przeniesionym do Wrocławia ${ }^{1}$.

1 W r. 1805 doktorat honorowy w Uniwersytecie Frankfurckim otrzymał np. Aleksander von Humboldt (1789-1855), znany niemiecki podróżnik, geograf i przyrodnik. Dyplom ten odnowił mu wrocławski Wydział Filozoficzny 4 VIII 1855 r.; por. Verzeichnis der Breslauer Universitätsschriften 1811-1855 [...] bearbeitet von Karl Pretzsch, Breslau 1905, s. 346, 355. 
Przybywający z zagranicy zwyczaj znalazł bardzo podatne podłoże w krakowskiej Wszechnicy. Wcześniej zresztą daje się zauważyć w Uniwersytecie szereg przypadków nadania doktoratów zbliżonych bardzo charakterem do honorowych, choć tak wyraźnie nie nazwanych. Ze względu na tryb ich nadania, z pominięciem nieraz wszelkich wymogów, jakie stawiały ówczesne przepisy o doktoratach kandydatom sięgającym po ten stopień akademicki (pisemnej rozprawy naukowej, rygorozów, czyli egzaminów doktorskich, i publicznej dysputy nad tezami doktorskimi), jak również częste motywowanie ich nadania zasługami naukowymi lub innymi względami, należalıby te doktoraty uznać za honorowe (określam je tutaj jako quasi honorowe). Spotyka się je również w późniejszym okresie (po r. 1817), obok tych nie budzących żadnej wątpliwości. Wszelka niepewność w tym względzie znika dopiero w odniesieniu do doktoratów nadanych po r. 1851. Odtąd bowiem - w myśl obowiązującego w cesarstwie austriackim dekretu Nadwornej Komisji Studiów z dn. 27 XII 1819 r. - zgodę na wyróżnienie doktorskim laurem honorowym wyrażał cesarz (za pośrednictwem Ministerstwa Wyznań i Oświaty).

Usankcjonowanie prawne nadawania w Uniwersytecie Jagiellońskim doktoratów h.c. nastąpiło w uchwalonym 12 VIII 1817 r. przez Komisję Organizacyjną Rzeczypospolitej Krakowskiej Wewnętrznym Urządzeniu Szkoły Głównej Krakowskiej (drukowane w r. 1818), którego paragraf 132 postanawiał, że ,uczeni cudzoziemscy szczególnej sławy lub znaczni protektorowie i dobrodzieje Szkoły Głównej mogą uzyskać stopień doktora bez oddzielnego egzaminu i dysertacji". Następne już Wewnętrzne Urzadzenie, załączone do Statutu Organicznego. UJ zwanego komisarskim (z r. 1833), uzyskany tym sposobem nazywa explicite honorowym.

Paragraf ten stosowano do r. 1851, chociaż od listopada 1846 r. Krakowski Uniwersytet znajdował się w granicach monarchii austriackiej. Dopiero Ministerstwo Wyznań i Oświaty zwróciło władzom akademickim Uczelni uwagę, że nie można nadawać doktorów h.c. bez zezwolenia cesarza.

W Polsce niepodległej szkoły akademickie uzyskawszy szeroki samorząd - przyznany im ustawą z 13 VII 1920 r. - otrzymały prawo nadawania doktorów honorowych. O zgodę na wyróżnienie kandydata za zasługi położone dla dobra naszej Ojczyzny i narodu polskiego względnie uniwersytetu zwracano się do ministra wyznań religijnych i oświecenia publicznego, natomiast przyznając doktorat za osiągnięcia naukowe, uczelnia nie musiała zabiegać o jego zatwierdzenie, gdyż zgodnie z obowiązującą od dawna zasadą szkoły akademickie cieszyły się całkowitą niezależnością w kwestiach naukowych. Postanowień tych nie zmieniono w narzuconej w r. 1933 szkołom akademickim ustawie zwanej jędrzejewiczow- 
ską. Obowiązywały one nawet początkowo w Polsce Ludowej (do grudnia 1951 r.).

W latach 1809 (1817)—-1837 i 1883-1931 Wydział Teologiczny UJ wyróżnił tytułem doktora teologii h.c. 64 księży, przy czym należy zauważyć, że Wydział ten dwukrotnie był pozbawiany prawa nadawania stopni doktorskich, a tym samym honorowych: najpierw wraz z pozostałymi wydziałami od czerwca 1811 do kwietnia 1814 r. ${ }^{2}$, potem w r. 1847 stracił prawo promocji na okres 33 lat do (1880 r.). Godnością doktora honorowego zaszczycił księży również Wydział Filozoficzny (10) oraz Wydział Prawa (2) i Wydział Lekarski (1). Ogółem nadano 77 doktoraty honorowe (w tym 4 osoby wyróżniono 2 dyplomami), z tego 38 w okresie przynależenia Uczelni do Rzeczypospolitej Krakowskiej, dużo mniej w czasach zaboru austriackiego (23), a tylko 5 w Polsce niepodległej. Z ogólnej liczby 73 katolickich duchownych doktorów honorowych UJ 61 stanowią Polacy lub cudzoziemcy naturalizowani w Polsce, resztę cudzoziemcy (12). Wśród nich było 13 profesorów lub zastępców profesorów w Uniwersytecie Jagiellońskim i 4 profesorów polskiego uniwersytetu w Warszawie. Nadto posiadało ten zaszczytny tytuł 23 arcybiskupów i biskupów (w tym 19 polskich), z których 7 otrzymało biret kardynalski. Wielu wyróżnionych zajmowało się twórczością naukową. Wśród tej plejady znakomitych osób zwrócić należy uwagę na trzech poprzedników kardynała Karola Wojtyły na stolicy biskupiej św. Stanisława Męczennika w Krakowie, a to kardynałów Albina Dunajewskiego, Jana Puzynę i Adama Sapiehę.

Pragnąc zaznaczyć związek z całością ziem wchodzących ongiś w skład państwa polskiego, nie zapomniała Alma Mater Jagellonica o Polakach działających w zaborze pruskim i rosyjskim (w Królestwie Polskim i na tzw. ziemiach zabranych), jak również austriackim (do listopada $1846 \mathrm{r}$.). $\mathrm{Z}$ całą wyrazistością uwidoczniło się to zwłaszcza w 1. połowie XIX w., ale i w późniejszym okresie Uniwersytet kierował się również tymi zasadami. Stosowano je oczywiście także na Wydziale Teologicznym. Najwięcej wyróżnionych księży pochodziło z Królestwa Polskiego (18) i z tzw. ziem zabranych (9, w tym bp A. Krasiński emigrant osiadły w Krakowie), obok 5 księży z zaboru pruskiego.

Poniższy poczet księży doktorów honoris causa UJ, zestawiony chronologicznie według daty przyznania tego tytułu (umieszczonej w nawiasie na końcu - najczęściej - poszczególnych notatek biograficznych. Gwiazdka * umieszczona po tej dacie oznacza quasi-doktorat honorowy ${ }^{3}$.

2 Niezbyt rygorystycznie przestrzegano tego zarządzenia, skoro zdarzały się w tym czasie promocje doktorskie (nie tylko honorowe), o czym świadczą wpisy do ksiąg doktorskich.

${ }^{3}$ Niniejsze zestawienie sporządziłem głównie na podstawie dwóch opracowan: H. Z wolska, M. Barcik, Tytuły, wyróżienia i godności honorowe Uniwer36 - Analecta Cracoviensia 
1. Florian K u d rewicz (1766-1834), bazylianin, biblista, proboszcz parafii greckokatolickiej w Krakowie, profesor UJ, reprezentant na Sejm i członek Senatu Rządzącego W. M. Krakowa (14 XII 1809)*.

2. Wincenty Józef Łańcucki (1756-1841), kaznodzieja działacz polityczny, archibrezbiter kościoła Mariackiego i scholastyk katedralny krakowski, kanonik katedralny żytomierski, zastępca profesora i rektor Uniwersytetu Jagiellońskiego (14 XII 1809)* .

3. Mikołaj Gilles (ok. 1752-1820), francuskiego pochodzenia, kanclerz kolegiaty Wszystkich Swiętych w Krakowie, kanonik katedralny krakowski, profesor dogmatyki na Uniwersytecie Krakowskim 19 I $1810)^{*}$.

4. Feliks J a roński (1777-1827), filozof, sekretarz i kanclerz konsystorza krakowskiego, profesor filozofii na Uniwersytecie Krakowskim potem w Seminarium Duchownego w Kielcach (30 VIII 1810) *.

5. Sebastian Alojzy Sierakow ski (1743-1824), architekt, filantrop, kanonik i prepozyt katedry krakowskiej, proboszcz parafii św. Floriana w Krakowie, rektor Uniwersytetu Krakowskiego (15 V 1811)*.

6. Jan Kanty Górnicki (1744-1817), misjonarz, rektor Seminarium Duchownego w Mohylowie, potem w Krakowie, superior domu misjonarzy w Krakowie, zastępca profesora i dziekan Wydziału Teologicznego Uniwersytetu Krakowskiego (15 III 1813)*.

7. Gabriel Józef Cedrowicz (1752-1828), kanonik metropolitalny gnieźnieński, kustosz kolegiaty w Choczu, proboszcz w Opatowie i Gołuchowie, potem w Słupach (17 VII 1813)*.

8. Adam U r banowi c z (1781-1838), kanonik honorowy kaliski, dziekan kaliski, oficjał generalny kaliski, pełnomocny zastępca proboszcza w Kościelnej Wsi k. Kalisza (8 XI 1814)*.

9. Józef M łodzianowski (XVIII/XIX w.), kanonik katedralny łucki (12 XI 1814)*.

10. Wojciech Anzelm Sze y kow ski (1773-1838), pijar, pedagog, pastoralista i homiletyk, językoznawca, prałat kustosz płocki, współorganizator i rektor Uniwersytetu Warszawskiego oraz jego profesor i dziekan Wydziału Teologicznego (6 X 1818).

11. Antoni Tafiłowski (ok. 1765-1831), kanonik honorowy i

sytetu Jagiellońskiego 1780-1978 (maszynopis w Archiwum UJ przygotowany do druku); T. Gl e m ma, Wydziat Teologiczny Uniwersytetu Jagiellońskiego $w$ latach 1795-1847, Kraków 1949. Uzupełnienia i korekty tych badań zostały przeprowadzone na podstawie źródeł z Archiwum UJ: rkps 393 s. 101-109, WT I 25-27, WP I 43, WF I $85,86,88$, WF II 481 , S I $308,362,414,415$. 
kanclerz katedralny żytomierski, dziekan radomyśleński, proboszcz parafii Korosteszów (6 X 1818).

12. Jan Marceli Gutkowski (1776-1863), scholastyk katedry płockiej i archidiakon kapituły warszawskiej, potem biskup podlaski, tytularny arcybiskup marcjanopolitański, naczelny kapelan wojska Królestwa Polskiego, zesłaniec (9 III 1819).

13. Józef Szczepan Koźmian (1773-1831), działacz oświatowy, kanonik metropolitalny warszawski, scholastyk katedralny lubelski, dziekan infułat kolegiaty zamojskiej, sufragan lubelski, potem biskup kujawski (9 III 1819).

14. Alojzy Chiarini (1789-1832), włoskiego pochodzenia hebraista i biblista, kanonik kapituły płockiej, profesor Uniwersytetu Warszawskiego (12 III 1819)

15. Stanisław Łow ecki (ok. 1787-po 1852), kanonik honorowy i wikariusz katedry łuckiej, profesor Seminarium Duchownego w Łucku (15 VII 1819).

16. Jakub Szarki ewicz (1776-1846), historyk Kościoła i kanonista, kanonik kapituły warszawskiej, profesor Seminarium Duchownego w Chełmnie, potem w Krakowie i Kielcach, profesor Uniwersytetu Warszawskiego, potem Akademii Duchownej w Warszawie (24 VIII 1820).

17. Stefan Kłodnicki (17?-1830), prepozyt katedry lubelskiej, regens i egzaminator diecezjalny lubelski, profesor Seminarium Duchownego w Krasnymstawie (6 XI 1820)*.

18. Jan B. Lavoisier (1766-1841), francuskiego pochodzenia tłumacz, kanonik katedralny mohylewski i wileński, proboszcz Pobojska, członek honorowy Uniwersytetu w Wilnie (31 III 1821)*.

19. Stanisław Czerski (1777-1833), filolog klasyczny, pedagog, kanonik katedry w Brześciu Litewskim i kanonik żmudzki, proboszcz parafii Sałarty na Żmudzi, profesor gimnazjum w Kijowie, potem w Wilnie (3 IV 1821)*.

20. Wincenty Pocisk-Dobrowolski (XVIII/XIX w.), kanonik katedralny łucki i prepozyt katedry żytomierskiej (22 VII 1824)*.

21. Mateusz Maurycy Wojakowski (1773-1845), archidiakon katedry lubelskiej, oficjał generalny, sufragan i wikariusz kapitulny lubelski (23 IX 1824)*.

22. Jan Mastelski (1782-1849), pastoralista, kanonik honorowy kielecki, dziekan kolegiaty Wszystkich Świętych i proboszcz kolegiaty św. Anny w Krakowie, kapelan i katecheta Liceum św. Anny i senior Bursy Jeruzalem, profesor Uniwersytetu Jagiellońskiego (28 I 1825)*.

23. Wawrzyniec Marczyński (1779-1845), historyk, pedagog, prałat kustosz katedry kamienieckiej i kanonik honorowy kielecki, katecheta i rektor szkoły wydziałowej w Kamieńcu Podolskim (30 I 1825) *. 
24. Paweł Straszyński (1784-1847), kanonik katedralny lubelski, kanonik, wicekustosz i prokurator kapituły metropolitalnej warszawskiej, administrator archidiecezji warszawskiej, potem biskup sejneński (4 X 1825)*.

25. Józef Gabriel Wy s ocki (1773-1847), dziekan prałat kolegiaty i oficjał kielecki, proboszcz parafii Kurzelów (20 III 1826).

26. Edward Czarnecki (1774-1831), zob. doktorzy medycyny h.c. (28 IX 1826).

27. Antoni Walczyński (1794-1837), kanonik katedralny krakowski i kolegiaty kieleckiej, regens i asesor konsystorza krakowskiego, proboszcz parafii Cierno, senator W.M. Krakowa (30 IX 1826).

28. Bernard Idzi Bzinkow ski (ok. 1767-1833), kanonik honorowy sandomierski, archidiakon kolegiaty kieleckiej, profesor i regens Seminarium duchownego w Kielcach (3 X 1826).

29. Antoni Onufry Bystrzon ow ski (1769-1848), filantrop, prałat kustosz i dziekan kapituły krakowskiej, komendataryjny opat mogilski, senator W. M. Krakowa (9 XI 1828).

30. Stanisław Lubicz-Wroczyński (XVIII/XIX w.), kanonik katedry łuckiej, członek konsystorza łuckiego, sekretarz metropolitalny w Mohylowie (9 I 1829)*.

31. Wojeiech Ossoliński (1796-1842), pastoralista i dogmatyk, archidiakon katedry podlaskiej, prepozyt kocki, profesor Uniwersytetu Warszawskiego, potem Akademii Duchownej w Warszawie, kapelan Gwardii Narodowej Warszawy w powstaniu listopadowym (27 IX 1829).

32. Ludwik Stanisław Łę tow ski (1786-1868), historyk i bibliofil, dziekan kapituły katedralnej krakowskiej, potem sufragan krakowski, administrator diecezji kielecko-krakowskiej, prepozyt stopnicki, prezes Towarzystwa Dobroczynności w Krakowie, senator W. M. Krakowa (14 X 1829)*.

33. Władysław Starczew ski (1768-1838), kanonik katedralny krakowski, reprezentant na Sejm W.M. Krakowa (8 XI 1830).

34. Józef Raciborski (1766-1840), kanonik kolegiaty Wszystkich Swiętych w Krakowie, proboszcz w Liszkach i dziekan czernichowski (13 IV 1831).

35. Ignacy Szynglarski (1786-1835), kanonik honorowy kolegiaty łowickiej, proboszcz parafii Bolimów, kapelan wojsk polskich powstania listopadowego, członek Towarzystwa Patriotycznego w Warszawie. więzień polityczny reżimu carskiego (17 VI 1831). W dniu 16 XI 1831 wykreślony $\mathrm{z}$ albumu doktorów na skutek decyzji rektora Alojzego Eistreichera, powziętej na polecenie władz zaborczych.

36. Antoni Łotocki (zm. przed 1837), kanonik honorowy lubelski, proboszcz w Iłży (27 VIII 1831)*. 
37. Ludwik Seweryn Gruszecki (1802-1860), kanonik kolegiaty łowickiej, regens kancelarii biskupiej, komendarz parafii św. Ducha w Łowiczu, proboszcz parafii Sobota (28 II 1832).

38. Leon Laurysiewicz (1798-1854), pastoralista, kanonik honorowy chełmski, proboszcz parafii greckokatolickiej w Krakowie, profesor i dziekan Wydziału Teologicznego UJ, rektor tegoż Uniwersytetu (20 II 1834$)^{*}$.

39. Franz Herman C z e ch (1788-1847), pijar, austriacki pedagog, prefekt i profesor Akademii Terezjańskiej, potem katecheta i dyrektor Instytutu Głuchoniemych w Wiedniu (26 V 1837).

40. Stanisław S p is (1843-1920), biblista i egzegeta, działacz oświatowy, kanonik katedralny krakowski, profesor Uniwersytetu Jagiellońskiego (17 III 1883).

41. Albin Dunajewski (1817-1894), książę-biskup krakowski, kardynał prezbiter (1 III 1885). Dyplom wręczyła biskupowi A. Dunajewskiemu w pałacu biskupim 10 III 1885 delegacja Uniwersytetu, złożona z profesorów Wydziału Teologicznego wraz dziekanem Józefem Pelczarem i rektorem Lucjanem Rydlem.

42. Jan Ignacy Korytkowski (1824-1888), historyk Kościoła, archiwista i bibliotekarz kanonik i oficjal gnieźnieński, delegat apostolski archidiecezji gnieźnieńskiej, sufragan nominat gnieźnieński (14 VI 1887).

43. Seweryn Tytus Morawski (1819-1900), historyk Kościoła, arcybiskup-metropolita lwowski obrządku łacińskiego (14 VI 1887). Dyplom wręczył arcybiskupowi S. Morawskiemu we Lwowie 21 VIII 1887 delegat Wydziału Teologicznego ks. Tadeusz Gromnicki.

44. Michał Nowodworski (1831-1896), biblista i patrolog, tłumacz i wydawca, biskup płocki (14 VI 1887).

45. Salvatore T a l a mo (1844-1932), włoski filozof neotomista i socjolog katolicki, prefekt i profesor Papieskiego Liceum i Seminarium Duchownego św. Apolinarego w Rzymie (1 III 1888).

46. Izaak Mikołaj I s a k ow i c z (1823-1901), homiletyk, kaznodzieja, arcybiskup-metropolita lwowski obrządku ormiańskiego (6 VIII 1898). Dyplom wręczył arcybiskupowi I. Isakowiczowi w pałacu arcybiskupim we Lwowie 21 IX 1898 delegat Uniwersytetu prorektor Władysław Knapiński. Wymagane wyznanie wiary złożył arcybiskup I. Isakowicz na ręce arcybiskupa Karola Hryniewieckiego, b. biskupa wileńskiego i kanonika kapituły metropolitalnej lwowskiej, w obecności prałata Kajetana Kajetanowicza i ks. Wiktora Wojaka, b. dziekana mińskiego.

47. Joachim Joseph Berthier (1848-1924), dominikanin, francuski dogmatyk, historyk Kościoła i hagiograf, profesor Katolickiego Uniwersytetu we Fryburgu (7 VI 1900). 
48. Ernst Commer (1847-1928), niemiecki filozof neotomista i dogmatyk, profesor Uniwersytetu we Wrocławiu, potem w Wiedniu (7 VI 1900).

49. Louis Marie Olivier D u che sne (1843-1922), francuski historyk Kościoła i archeolog, dyrektor Ecole Française w Rzymie (7 VI $1900)$.

50. Henryk Piotr Kossowski (1828-1903), dogmatyk i historyk Kościoła, rektor Rzymsko-Katolickiej Akademii Duchownej w Warszawi , sufragan płocki, potem włocławski (7 VI 1900).

51. Stanisław Leopold K u jot (1845-1914), historyk i powieściopisarz, publicysta i działacz społeczny, proboszcz w Grzybnie, prezes Towarzystwa Naukowego w Toruniu (7 VI 1900).

552. František Xaverius L a u r in (1829-1913), czeski kanonista, profesor Uniwersytetu w Wiedniu (7 VI 1900).

53. Mieczysław Jan Halka-Ledóchowski (1822-1902), dyplomata papieski, arcybiskup gnieźnieński i poznański, kardynał, prefekt generalny Kongregacji Rozkrzewienia Wiary (7 VI 1900).

54. Edward Likowski (1836-1915), historyk Kościoła, arcybiskup gnieźnieński i poznański, prezes Towarzystwa Przyjaciół Nauk w Poznaniu (7 VI 1900).

55. Lucido Maria Parocchi (1833-1903), włoski dogmatyk, kaznodzieja, biskup Pawii, potem arcybiskup Bolonii, biskup Albano, biskup Porto i Santa Rufina, wikariusz papieski diecezji rzymskiej, kardynał i poddziekan Kolegium kardynalskiego, wicekanclerz Kurii rzymskiej, sekretarz Kongregacji św. Oficjum, protektor Kolegium polskiego zmartwychwstańców i zakonów polskich w Rzymie (7 VI 1900).

56. Adolphe Louis Albert Perraud (1829-1906), oratorianin, francuski historyk Kościoła i apologetyk, generał Zgromadzenia oratorianów, biskup autuński i kardynał, opiekun uchodźców polskich we Francji (7 VI 1900).

57. Jan Maurycy Paweł Puz y n a (1842-1911), sufragan metropolii lwowskiej, potem książę-biskup krakowski, kardynał (7 VI 1900).

58. Charles de Smedt (1833-1911), bollandysta, belgijski dogmatyk, hagiograf i historyk Kościoła, wydawca źródeł, prezydent bollandystów (7 VI 1900).

59. Hermann Z s hokke (1838-1920), austriacki biblista i egzegeta, historyk Kościoła, profesor uniwersytetu w Wiedniu, sufragan metropolii wiedeńskiej (7 VI 1900).

60. Désiré Joseph M e r cie r (1851-1926), belgijski neotomista i pastoralista, profesor Katolickiego Uniwersytetu w Lowanium, założyciel i dyrektor Institut Supérieur de Philosophie, tegoż uniwersytetu, arcybiskup-metropolita mechliński i prymas Belgii, kardynał, przyjaciel Po- 
laków (23 XII 1918). W imieniu Uniwersytetu wręczył dyplom kardynałowi D. Mercierowi w arcybiskupiej siedzibie w Malines 23 II $1920 \mathrm{mi}-$ nister pełnomocny polski w Królestwie Belgii Władysław Sobański.

61. Adam Stefan Stanisław S a p i e h a (1867-1951), książę-biskup krakowski, potem arcybiskup-metropolita krakowski, kardynał, (27 IV 1926). Dyplom wręczyli arcybiskupowi A. Sapieże w jego rezydencji biskupiej 18 VI 1926 profesorowie Wydziału Teologicznego wraz dziekanem ks. Maciejem Sieniatyckim i rektor UJ Michał Rostworowski.

62. Stanisław Ok on ie w ski (1870-1944), historyk Kościoła, mecenas sztuki, biskup chełmiński (27 IV 1926).

63. Arkadiusz Marian Lis i e k i (1880-1930), historyk Kościoła, działacz oświatowy, społeczny i polityczny, biskup katowicki (16 XII 1929). Dyplom wreczyła biskupowi A. Lisieckiemu w jego siedzibie biskupiej w Katowicach 16 XII 1929 delegacja Uniwersytetu z rektorem Henrykiem Hoyerem i przedstawiciele Wydziału Teologicznego: ks. dziekan Antoni Bystrzonowski, ks. Józef Kaczmarczyk, ks. Józef Archutowski i ks. Władysław Grzelak w obecności wojewody śląskiego dra Michała Grażyńskiego.

64. Teodor Filip $\mathrm{Kubina}(1880-1951)$, teoretyk i działacz katolickiego ruchu społecznego, biskup częstochowski (13 XII 1931). Uroczyste wręczenie dyplomu odbyło się w auli Częstochowskiego Seminarium Duchownego w Krakowie z udziałem ks. rektora UJ Konstantego Michalskiego i profesorów Wydziału Teologicznego z ks. dziekanem Józefem Archutowskim i ks. prof. Antonim Bystrzonowskim jako promotorem, w obecności przedstawicieli duchowieństwa i licznych gości.

DOKTORZY OBOJGA PRAW HONORIS CAUSA

1. Jan Chrzciciel Schindler (1802-1890), niemieckiego pochodzenia biblista, działacz polityczny, archidiakon kapituły katedralnej krakowskiej, komendataryjny opat mogilski, profesor Uniwersytetu Jagiellońskiego, senator i prezes Senatu Rządzącego W.M. Krakowa (4 VII 1833).

2. Mateusz G $\nmid$ a d yszewicz (1798-1862), historyk, kanonik honorowy kolegiaty Wszystkich Swiętych w Krakowie, prałat kustosz kapituły katedralnej krakowskiej, wikariusz kapituły wikariatu krakowskiego (2 VII 1893). 
III

\section{DOKTOR MEDYCYNY HONORIS CAUSA}

1. Edward Czarnecki (1774-1831), pijar, pedagog, kanonik katedralny płocki, prałat kustosz metropolitalny i wikariusz kapitulny warszawski, członek Towarzystwa do Ksiąg Elementarnych, sekretarz Towarzystwa Przyjaciół Nauk w Warszawie (7 II 1818).

IV

DOKTORZY FILOZOFI HONORIS CAUSA

1. Feliks Ja roński (1777-1827), zob. wyżej doktorzy teologii h.c. $(12 \mathrm{X} 1811)^{*}$.

2. Piotr Wawrzyniec Bou cher (ok. 1764-1821), francuskiego pochodzenia romanista, kanonik kapituły kolegiackiej kieleckiej i kapituły katedralnej krakowskiej, profesor Uniwersytetu Krakowskiego (18 I 1812)*.

3. Jakub Falkowski (1775-1848), pijar, pedagog głuchoniemych, kanonik honorowy kapituły metropolitalnej warszawskiej, proboszcz parafii soleckiej, założyciel, nauczyciel i rektor Instytutu Głuchoniemych w Warszawie (22 V 1816).

4. Franciszek Ksawery St a ch ow ski (1790-1850), białoruskiego pochodzenia katecheta, archiprezbiter kościoła Mariackiego i dziekan kolegiaty Wszystkich Swiętych w Krakowie, kaznodzieja i kanonik katedralny krakowski, sekretarz konsystorza krakowskiego, profesor Uniwersytetu Jagiellońskiego (18 VI 1837)*.

5. Franz Hermann $\mathrm{Czech}$ (1788-1847), zob. doktorzy teologii h.c. (7 VI 1839).

6. Jan Chrzciciel Schindle r (1802-1890), zob. doktorzy obojga praw h.c. (12 IV 1840).

7. Sebastian Brunner (1814-1893), austriacki publicysta katolicki, poeta i prozaik, historyk Kościoła (13 III 1845).

8. Jan Piotr Z i enkiewicz (1797-1874), bibliotekarz, kanonik i prezydent kapituły katedralnej gnieźnieńskiej, oficjał i wikariusz generalny gnieźnieński (17 VI 1847).

9. Jan Staroniewicz (1821-1858), biblista i egzegeta, pastoralista i katecheta, profesor Uniwersytetu Jagiellońskiego (20 I 1850).

10. Adam Stanisław Krasiński (1810-1891), językoznawca semazjolog i polonista, tłumacz, poeta, kanonista, biskup wileński, zesłaniec i emigrant (14 VI 1887). 
Grono profesorskie Wydziału Teologicznego UJ pragnęło również ujrzeć wśród wyróżnionych doktorem honorowym teologii: ks. Tadeusza Gromnickiego (1851-1939), kanonistę i historyka Kościoła, profesora Uniwersytetu Jagiellońskiego; ks. Juliana Kuiłowskiego (1826-1900), arcybiskupa lwowskiego i metropolitę halickiego obrządku greckokatolickiego; ks. Józefa Teofila Teodorowicza (1864-1938), biblistę i pisarza religijnego, kaznodzieję, arcybiskupa-metropolitę obrządku ormiańskiego, działacza politycznego. Niestety życzenia te nie spełniły się i żaden z tych kandydatów nie otrzymał dyplomu.

Propozycję nadania ks. T. Gromnickiem u tytułu doktora h.c. w uznaniu jego osiągnięć naukowych wysunął dziekan Józef Pelczar. Uchwała kolegium profesorskiego Wydziału z 30 X 1890 r. przesłana do Ministerstwa Wyznań i Oświaty w Wiedniu w celu zatwierdzenia nie doczekała się niestety aprobaty cesarskiej.

Na wyróżnienie abpa J. Kuiłow skiego ,za jego wielkie zaslugi wobec Kościoła katolickiego ritus graeci w naszym kraju [Galicji MB! i za jego zasługi wobec bratniego narodu ruskiego" zgodziło się kolegium profesorskie Wydziału 21 XII 1809 r., czyniąc tym zadość Senatowi Akademickiemu UJ, który wystąpił z tą propozycją. Niestety zgon abpa J. Kuiłowskiego (4 V 1900) uczynił uchwałę bezprzedmiotową.

Powziętą jednomyślnie 4 VI 1937 r. przez Radę Wydziału uchwałę o wyróżnienie doktoratem h.c. abpa J. Teodorowicza ,w związku z Jego złotymi godami kapłaństwa" zaaprobował Senat Akademicki UJ w dniu 8 tm., biorąc pod uwage działalność naukową kandydata. Ponieważ uchwała ta przesłana została do Kongregacji Studiów Kurii Rzymskiej (chociaż ustawa o szkołach akademickich z r. 1933 tego nie przewidywała), udał się tam rektor Papieskiego Instytutu Polskiego w Rzymie ks. Tadeusz Zakrzewski, ,by prosić o przyspieszenie procedury i wytłumaczyć powody tej prośby" (o wyrażenie zgody na udzielenie abp. Teodorowiczowi doktoratu h.c. - MB). Nie mogąc ,zapewnić, czy interwencja ta odniesie pożądany skutek i czy zdecydują się na odstąpienie od zwykłego biegu w traktowaniu spraw”, przyrzekł ,w każdym razie jeszcze za kilka dni" ponowić interwencję. Ks. T. Zakrzewski nie odniósł prawdopodobnie pożądanego rezultatu, bo do promocji nie doszło, a w półtora roku później zmarł abp J. Teodorowicz (4 XII 1938).

Ostatnia promocja doktora teologii h.c. odbyła się w krakowskiej Wszechnicy ponad pół wieku temu (13 XII 1931), a zabiegi jej Wydziału Teologicznego o wyróżnienie abpa J. Teodorowicza okazały się w historii Uczelni ostatnią próbą nadania kapłanowi tego zaszczytnego tytu$1 \mathrm{x}$.

W latach powojennych Wydział zajęty odbudową teologii w środowisku 
krakowskim nie podejmował w tym kierunku inicjatywy, choć nadarzała się po temu okazja, jaką stworzył w r. 1947 obchód 550-letniej rocznicy ustanowienia fakultetu teologicznego w Krakowie. W późniejszym zaś trudnym dla Kościoła katolickiego i jego instytucji okresie stalinowskich „,błędów i wypaczeń” tym bardziej trudno było myśleć o takich drobiazgach, zwłaszcza po uchwaleniu ustawy o szkolnictwie wyższym i pracownikach nauki (15 XII 1951), odkąd to przewidywane usunięcie Wydziału Teologicznego z UJ było tylko kwestią czasu.

Wznawiając w styczniu 1945 r. jawną działalność, po przeszło pięcioletniej, straszliwie wyniszczającej, okupacyjnej nocy, nie przypuszczało grono pedagogiczne Wydziału Teologicznego UJ, że wbrew jego stanowisku za niespełna 10 lat (1 XI 1954), wskutek arbitralnej decyzji władz rządowych, nastąpi wyłączenie Wydziału ze struktury Uniwersytetu. Nie uchroniła go od tego bolesnego postanowienia 558-letnia tradycja zespalająca naukę o Bogu z całością Wszechnicy Jagiellońskiej; pominięto przy tym moc prawną i przestrogę bulli erygującej Wydział papieża Bonifacego X (11 I 1397), która m.in. stwierdzała, że ,żadnemu człowiekowi nie wolno tej karty naszego rozporządzenia, postanowienia i nadania złamać, albo z zuchwałym uporem jej się sprzeciwiać. Gdyby zaś ktoś się na to odważył, niech wie, że działa przeciwko Wszechmocnemu Bogu i świętym Jego Apostołom Piotrowi i Pawłowi" 4 .

AN DER JAGELLONEN-UNIVERSITÄT IN DEN JAHREN 1809-1931 MIT DEM EHRENDOKTORTITEL AUSGEZEICHNETE KATHOLISCHE GEISTLICHE

\section{Z us a m m e $\mathrm{n} f$ ass ung}

Die Gepflogenheit der Verleihung der Ehrendoktorwürde wurde an der Jagellonen-Universität in Krakau von den deutschen Universitäten zu Beginn des 19. Jhs. übernommen (z. B. wurde 1805 von der im Jahre 1811 nach Breslau verlegten Frankfurter Universität der Titel doctor homoris causa Alexander von Humboldt verliehen).

Bei der Verleihung dieses Titels hielt sich der Senat der Krakauer Universität an drei Kriterien: wissenschaftliche Errungenschaften, Verdienste um das Vaterland und die polnische Nation sowie Verdienste um die Krakauer Universität. Die Promotion zum Doktor der Kandidaten (besonders fremder), ohne daß diese die akademischen Anforderungen erfüllen mußten (z.B. die Vorlage einer Dissertation,

${ }_{4}$ Cytat $\mathrm{z}$ polskiego przekładu bulli Bonifacego X, zamieszczonego w: „Analecta Cracoviensia" 9 (1977) s. 8. Por. dawniejszy, nieco odmienny przekład Stanisława Krzyża nowskiego: Poselstwo Kazimierza Wielkiego do Awinionu i pierwsze uniwersyteckie przywileje, „Rocznik Krakowski” 4 (1900) s. 104. 
das Ablegen des Rigorosums, das Abhalten einer öffentlichen Diskussion über die Dissertationsthesen) wurde an der Jagellonen-Universität seit der von der Organisationskommission der Krakauer Republik am 12. 08. 1817 erlassenen Verordnung vorgenommen. Jedoch handelte es sich dann um quasi-Ehrendoktorate (im obigen Verzeichnis mit * versehen). Erst im Jahre 1833 wurde ins Universitätsgesetz ein Paragraph über die Ehrendoktorate explizite aufgenommen.

Im obengenannten Zeitraum wurde von der Theologischen Fakultät die Ehrendoktorwürde 64 katholischen Geistlichen verliehen, 10 - von der Philosophischen Fakultät, 2 - von der Rechtsfakultät und 1 - von der Medizinischen Fakultät. Insgesamt wurden 77 Personen der Ehrendoktortitel verliehen (darunter 4 Gelehrten durch zwei Fakultäten).

Die letzte (und eine einzige nach dem zweiten Weltkrieg) Promotion eines Geistlichen zum Ehrendoktor fand an der Jagellonen-Universität am 22. 06. 1983 statt: es war Papst Johannes Paul II., dem damals diese höchste akademische Würde von der Hochschule, an der er einstmals studierte, verliehen wurde. 